\title{
Air Quality Toxicity Index (AQTI): Quantifying Air Pollution Impact on Disease Onset
}

\author{
Harold I. Zeliger
}

\begin{abstract}
Air pollution impacts $90 \%$ of the world's population and is the number one cause of premature deaths worldwide, estimated at 8-10 million per year. Breathing polluted air is associated with the accelerated onset of numerous illnesses, including respiratory diseases, cardiovascular diseases, several cancers and Alzheimer's disease. Five major air pollutants are typically monitored in cities around the world for air quality. These include ozone, particulate matter, sulfur dioxide, nitrogen dioxide and carbon monoxide. The Air Quality Toxicity Index (AQTI), that is first reported here provides a quantitative indicator with which to monitor air quality, make air quality comparisons of different locations and compare air quality of the same locations as a function of time.
\end{abstract}

Index Terms-Air pollution toxicity, disease onset, air pollution and disease.

\section{INTRODUCTION}

Air pollution impacts $90 \%$ of the world's population and is the number one cause of premature deaths, estimated at 810 million per year worldwide [Combes and Franchineau, 2019; World Health Organization, 2018]. Breathing polluted air is associated with the accelerated onset of numerous illnesses, including respiratory diseases, cardiovascular diseases, several cancers and Alzheimer's disease [Zhou, et al., 2019; Xia, et al., 2019; Kilian J and Kitazawa M, 2018].

Five major air pollutants are typically monitored for air quality. These include ozone, particulate matter, sulfur dioxide, nitrogen dioxide and carbon monoxide. In America, the United States Environmental Protection Agency (EPA) measures air quality in multiple locations on a daily basis and reports the data on-line daily as the Air Quality Index (AQI) [EPA, 2019]. Worldwide, the World Air Quality Project similarly reports air quality data for hundreds of cities. [World Air Quality Index Project, 2019]. On an annual basis, these indices identify the number of days in which the air quality is classified as either good, moderate, unhealthy for sensitive groups, unhealthy, very unhealthy or hazardous.

All of the pollutants identified above impact the human body by increasing oxidative stress, known to trigger disease onset, in a dose response relationship [Riggs, et al., 2020; Zeliger, 2016.; Kelly, 2003]. Disease onset can be rapid, resulting from an acute exposure to a high concentration of an air pollutant, an example of such a

Published on January 16, 2020.

Harold I. Zeliger, Zeliger Research, LLC 41 Wildwood Drive Cape Elizabeth, Maine, USA.

(e-mail: a hiz@zeliger.com) response being the London smog of 1952 that was responsible for as many as 12,000 deaths and the onset of 100,000 health conditions [Bell, et al., 2004]. Disease can also develop over time from chronic exposure to lower air pollution levels. An example of this phenomenon is the high levels of respiratory disease in several Chinese cities with consistent elevated air pollution values [Zhou, et al., 2019].

Given the dose response relationship between air pollution and disease onset as well as varying air pollutant concentrations, it is difficult to assess the likelihood of disease onset just from the number of days of air pollution concentrations at different levels. For example is a ten day exposure to air classified as "unhealthy" more or less toxic overall than a thirty day exposure to air classified as "moderate ?" The Air Quality Toxicity Index (AQTI), that is first reported here, addresses this uncertainty by providing a quantitative value for assessing total annual air pollution toxic exposure. Using the AQTI, it becomes possible to compare overall air quality for different locations and compare air quality in the same locations as a function of time.

\section{METHODS}

\section{Air Quality Toxicity Index (AQTI) Calculation}

The EPA (AQI) classifications for air quality are shown in table 1 [EPA 2019]. Other air quality indices may be similarly classified. Hazard numbers are assigned here to each classification ranging from 1-6, with 1 for good air quality through 6 for hazardous air quality, as also shown in Table 1.

TABLE 1. EPA Air Quality Index classifications.

\begin{tabular}{|c|c|c|}
\hline EPA AQI & EPA Classification & $\begin{array}{c}\text { Hazard } \\
\text { Number }\end{array}$ \\
\hline 0 to 50 & Good & 1 \\
\hline 51 to 100 & Moderate & 2 \\
\hline 101 to 150 & $\begin{array}{c}\text { Unhealthy for } \\
\text { Sensitive Groups }\end{array}$ & 3 \\
\hline 151 to 200 & Unhealthy & 4 \\
\hline 201 to 300 & Very Unhealthy & 5 \\
\hline 301 to 500 & Hazardous & 6 \\
\hline
\end{tabular}

EPA also reports the number of days per year that fall into each air quality classification. The AQTI is calculated by multiplying the hazard number $(\mathrm{HN})$ by the number of days in a given year that air quality corresponds to each number and then totaling the numbers to generate the AQTI for that location, as shown by the following 
equation.

$\mathrm{AQTI}=(1) \mathrm{x}($ Days at HN 1) + (2) $\mathrm{x}($ Days at HN 2) + (3) $\mathrm{x}$ (Days at HN 3) +

(6) $\mathrm{x}$ (Days at HN 6)

(4) $\mathrm{x}($ Days at HN 4) + (5) x (Days at HN 5) +

As examples, Table 2 shows the calculation of AQTI numbers that were thus generated for three American cities in the year 2018: Houston, Texas (HT); Los Angeles, California (LA); and Portland, Maine (PM).

Table 2. AQTI calculation for three American cities. HT = Houston Texas; LA =Los Angeles; California; PM = Portland Maine.

\begin{tabular}{|l|l|l|l|l|l|l|l|}
\hline & Multiplier & \multicolumn{3}{|l|}{$\begin{array}{l}\text { Days of Each City } \\
\text { at Each Level }\end{array}$} & \multicolumn{3}{|c|}{$\begin{array}{l}\text { Multiplier Times } \\
\text { Days } \\
\text { at Each Level }\end{array}$} \\
\hline & & \multicolumn{1}{|l}{ HT } & LA & PM & HT & LA & PM \\
\hline Good & 1 & 166 & 35 & 311 & 166 & 35 & 311 \\
\hline Moderate & 2 & 164 & 220 & 2 & 328 & 440 & 104 \\
\hline $\begin{array}{l}\text { Unhealthy } \\
\text { for Sensitive } \\
\text { Groups }\end{array}$ & 3 & 26 & 90 & 3 & 78 & 270 & 6 \\
\hline Unhealthy & 4 & 7 & 19 & 0 & 28 & 76 & 0 \\
\hline $\begin{array}{l}\text { Very } \\
\text { Unhealthy }\end{array}$ & 5 & 2 & 1 & 0 & 10 & 5 & 0 \\
\hline Hazardous & 6 & 0 & 0 & 0 & 0 & 0 & 0 \\
\hline & & & & & & & \\
\hline
\end{tabular}

AQTI values can be used to determine an area's overall annual air quality classification, as shown in Table 3.

\begin{tabular}{|c|c|}
\hline $\begin{array}{c}\text { AIR QUALITY } \\
\text { CLASSIFICATION }\end{array}$ & AQTI \\
\hline Good & $365-450$ \\
\hline Moderate & $451-600$ \\
\hline $\begin{array}{c}\text { Unhealthy for } \\
\text { Sensitive Groups }\end{array}$ & $601-750$ \\
\hline Unhealthy & $751-900$ \\
\hline Very Unhealthy & 901-1050 \\
\hline Hazardous & 1051 or higher \\
\hline
\end{tabular}

\section{RESULTS}

As can be seen from the data for the three cities in tables 2 and 3, Portland, Maine's 2018 air quality overall was good. Houston's 2018 air quality overall was unhealthy for sensitive groups and the air in Los Angeles 2018 overall was unhealthy 2018. AQTI values calculated for 2016 - 2018 show how air quality varied over three years for each of these cities. These are shown in Table 4.

Table 4. AQTI values for three American cities 2016-2018

\begin{tabular}{|c|c|c|c|}
\hline & $\begin{array}{c}\text { Houston, } \\
\text { Texas }\end{array}$ & $\begin{array}{c}\text { Los Angeles, } \\
\text { California }\end{array}$ & Portland, Maine \\
\hline 2016 & 592 & 837 & 407 \\
\hline 2017 & 574 & 868 & 415 \\
\hline 2018 & 650 & 826 & 421 \\
\hline
\end{tabular}

As can clearly be seen from the data, air quality did not vary much in these cities over a three year period.

\section{DISCUSSION}

The AQTI data quantified here are believed to accurately represent the true impact of air pollution on health for the following reason. All air pollutants are toxic to humans because they elevate oxidative stress in a dose response relationship (DRR) [Zeliger, 2016; Kelly, 2003] Accordingly, it is total toxic dose that determines health impact. The size of the dose can vary from day to day, but total dose of exposure is additive and may come from varying daily doses. Such a relationship is also demonstrated by the health impact of other toxic exposures. Examples of these are smoking cigarettes, where smoking intensity is indicative of disease levels observed [Nance, et al., 2017] and radon exposure where health impact is based upon total radiation exposure [Lubin, et al., 1997].

AQTI values make it possible to quantify overall air quality, make comparisons of air quality in different locales and examine the air quality of a city or region as a function of time. This removes the uncertainty associated with trying compare air quality for areas with differing numbers of days with good, moderate, unhealthy for sensitive groups, unhealthy, very unhealthy or hazardous air quality.

The AQTI does have limitations. It does not take into account unusual local events, such as chemical plant explosions and releases as well as unusual events such as severe storms, forest fires and volcano eruptions which can affect air quality for periods of time. Such events, which account for the elevated AQTI numbers for Los Angeles in 2017 and Houston in 2018 can be factored out by considering AQTI values for years in which such occurrences were absent. Also, the AQTI only considers outdoor air quality and not indoor air quality. Though indoor air quality is certainly a contributor to adverse health, it can only be assessed on an individual basis, as it can vary widely from building to building. All residents of a given locale, however, are subject to the impacts of outdoor air pollution.

\section{CONCLUSION}

The AQTI described here can be used to quantify air pollution classifications for given regions. These values can be used to compare differences in air quality in different locales or in the same locale as a function of time.

\section{REFERENCES}

S. Chen, B. Mulgrew, and P. M. Grant, “A clustering technique for digital communications channel equalization using radial basis function networks," IEEE Trans. on Neural Networks, vol. 4, pp. 570-578, July 1993.

Bell, ML, Davis DL, Fletcher T. 2004. A retrospective assessment of mortality from the London smog episode of 1952: The role of influenza and pollution. Environ Health Perspect; 112(1):6-8.

Combes A, Franchineau G. 2019. Fine particle environmental pollution and cardiovascular diseases. Metabolism, 2019. doi: 10.16/j.metabol.2019.07.008

EPA. 2019. Air quality index (AQI). https://airnow.gov/index.cfm?action=aquibasics.aqi. Accessed January 2, 2020.

Kelly FJ. 2003. Oxidative stress: Its role in air pollution and adverse health effects. Occup Environ Med 60:612-616. 
Kilian J, Kitazawa M. 2018. The emerging risk of exposure to air pollution on cognitive decline and Alzheimer's disease - Evidence from epidemiological and animal studies. Biomed J 41(3):141-162.

Lubin JH, Tomasek L, Edling C, Hornung RW, Howe G, Kunz E, et al. 1997. Estimating lung cancer mortality from residential radon using date for low exposure miners. Radiat Res; (147(2):126-34.

Nance R, Delaney J, McEviy JW, Blaha MJ, Burke GL, Navas-Acien A, et al. 2017. Smoking intensity (pack/day) is a better measure than packyears or smoking status for modeling cardiovascular disease outcomes. J Clin Epidemiol. 2017. doi: 1016/j.jclinepi.2016.09.010

Riggs DW, Zafar N, Krishnasamy S, Yeager R, Rai, SN, Bhatnagar A O'Toole TE. 2020. Exposure to airborne fine particulate matter is associated with impaired endothelial function and biomarkers of oxidative stress and inflammation. Environ Res. 2020. doi: 10.1016/j.envres.2019.108890. Accessed December 30, 2019.

World Air Quality Index Project. 2019. https://aqicn.com

World Health Organization. 2018. Air pollution. WHO global ambient air quality database (update 2018). https://www.who.int/airpollution/data/cities/en. Accessed December 30, 2019.

Xia SY, Huang DS, Jia H, Zhao Y, Lin N, Mao MQ, et al. 2019. Relationship between atmospheric pollutants and risk of death caused by cardiovascular and respiratory diseases and malignant tumors in Shenyang, China from 2013to 2016: an ecological research. Chin Med J (Engl); 132(19):2269-2277.

Zeliger HI. 2011. Human toxicology of chemical mixtures. Elsevier, London.

Zeliger HI. 2016. Predicting disease onset in clinically healthy people. Interdiscip Toxicol 9(2):15-21.

Zhou H, Wang T, Zhou F, Liu Y, Zhao W, Wang X, et al. 2019. Ambient air pollution and daily hospital admissions for respiratory disease in children in Guiyang, China. Front Pediatr, 2019. doi: 10.3389/fped.2019.00400 